\title{
RETENÇÃO DE ZINCO EM SOLOS PAULISTAS $\left({ }^{1}\right)$
}

\author{
RODRIGO CÉSAR DE ARAÚJO CUNHA $\left({ }^{2}\right)$; \\ OTÁVIO ANTONIO DE CAMARGO $\left({ }^{3,5}\right)$ e TOSHIAKI KINJO $\left({ }^{4}\right)$
}

\begin{abstract}
RESUMO
Para avaliar os atributos do solo que têm maior influência na retenção de zinco, desenvolveram-se experimentos de laboratório com amostras de horizontes superficial e subsuperficial de quatro latossolos, dois podzólicos e uma terra roxa estruturada de grande importância geográfica c econômica no Estado de São Paulo. No experimento de retenção, as amostras foram equilibradas com soluções de $\mathrm{Zn}$ nas concentrações $0,0,0,3,0,6,0,9,1,5,3,0,6,0,9,0,12,0$ e $24,0\left(\mathrm{x} 10^{-3}\right) \mathrm{mg} / \mathrm{dm}^{3}$ de $\mathrm{Zn}$ usando-se uma solução de $\mathrm{CaCl}_{2}$ na concentração de $2 \mathrm{~mol} / \mathrm{m}^{3}$ como suporte. Correlacionaram-se os coeficientes das equações de Langmuir e Freundlich com os diversos atributos do solo. Tendo em vista a possibilidade de estimar a energia de ligação e a adsorção máxima de zinco pelos coeficientes da equação de Langmuir, verificaram com auxílio de regressões linear simples e múltipla as correlações entre os atributos e esses coeficientes. Considerando a análise de regressão múltipla como o procedimento mais adequado, verificou-se que o coeficiente relativo de energia de ligação mostrou-se mais bem correlacionado com o $\mathrm{pH}$, o Fe extraído com oxalato e o Al extraído com ditionito. Para a adsorção máxima, o $\mathrm{pH}$ e a CTC foram as propriedades que melhor explicaram esse coeficiente.
\end{abstract}

Termos de indexação: zinco, retenção, propriedades do solo.

\section{ABSTRACT \\ ZINC RETENTION IN SOILS OF THE STATE OF SÃO PAULO, BRAZIL}

Soil atributes that influence the most on zinc retention in the State of São Paulo, Brazil, were evaluated. Laboratory assays were developed with samples from surface and subsurface horizons of the following: four latosols, two podzolics, and one "terra roxa estruturada". Zinc retention was evaluated by equilibrating the samples with solutions containing $0.0,0.3,0.6,0.9,1.5,3.0,6.0,9.0,12.0$ and $24.0 \mathrm{mg} / \mathrm{dm}^{3}$ of $\mathrm{Zn}$, using $\mathrm{CaCl}_{2}$ solution in the concentration of $2 \mathrm{~mol} / \mathrm{m}^{3}$ as support. Coefficients of the Langmuir and Freundlich equations were correlated with several soil attributes.

( ${ }^{1}$ ) Recebido para publicaçāo em 18 de fevereiro e aceito em 21 de setembro de 1994.

$\left({ }^{2}\right)$ CETESB, Av. Prof. Frederico Hermann Jr., 345, 04489-900, São Paulo (SP).

$\left.{ }^{3}\right)$ Seção de Pedologia, Instituto Agronômico, Caixa Postal 28, 13001-970, Campinas (SP).

$\left({ }^{4}\right)$ Departamento de Ciência do Solo, Escola Superior de Agricultura "Luiz de Queiroz", Caixa Postal 09, 13418-900 Piracicaba (SP).

$\left({ }^{5}\right)$ Com bolsa de pesquisa do CNPq. 
Taking into consideration that binding energy and maximum adsorption of zinc can be evaluated by the coefficients of the Langmuir equation, correlations were obtained using simple linear and multiple regression analysis. Through multiple regression it was evidenced that binding energy was mostly correlated with $\mathrm{pH}$, Fe extracted with ammonium oxalate, and aluminum extracted with citrate-dithionite-bicarbonate. The maximum adsorption was better related to $\mathrm{pH}$ and CEC.

Index terms: zinc, retention, soil properties.

\section{INTRODUÇÃO}

São inúmeros os fatores que podem afetar a adsorção de zinco no solo. Se os mecanismos de retenção envolvidos forem reações de precipitação-dissolução, adsorção-dessorção ou complexação, sofrerão a influência do $\mathrm{pH}$, da atividade microbiana, do potencial de oxirredução, da composição química e mineralógica do solo e da composição química de sua solução, entre outros fatores.

Segundo Lindsay (1979), os óxidos, hidróxidos, carbonatos e silicatos de zinco são muito pouco solúveis para que possam responder pela concentração de zinco solúvel nos solos. Na sua opinião, os processos de adsorção aos constituintes do solo parecem ser os principais mecanismos controladores da dinâmica do zinco nesse meio.

Maior retenção de zinco tem sido observada em solos com pH elevado. Forbes et al. (1976) verificaram que a valores de $\mathrm{pH}$ iguais a 5,9 apenas $11 \%$ do zinco adicionado era adsorvido, contra $61 \%$ quando o pH era elevado a 7,2. Para Shuman (1986), essa maior adsorção está relacionada às cargas elétricas dependentes do $\mathrm{pH}$. Sposito (1982) explica que, com a elevação do $\mathrm{pH}$, o zinco é complexado por $\mathrm{OH}^{-}$e mesmo a valores de $\mathrm{pH}$ menores que sua constante de estabilidade, metade da quantidade de $\mathrm{ZnOH}^{-}$é adsorvida.

A formação de complexos orgânicos é um dos importantes mecanismos de retenção do zinco no solo. A presença da matéria orgânica pode controlar não apenas a retenção, mas, também, a especiação iônica na solução do solo, sendo a formação de complexos solúveis o mecanismo responsável pela manutenção dos níveis de zinco em solução (Hodgson et al., 1966). São inúmeros os ácidos orgânicos que têm sido identificados no solo, entre esses, os di- e os tricarboxílicos são, segundo Stevenson \& Ardakani (1972), os mais eficientes na formação de complexos estáveis com os metais. Ainda de acordo com esses autores, tanto os ácidos húmicos como os fúlvicos podem formar complexos solúveis com os metais polivalentes.

Essas ligações podem-se dar, ainda, segundo Stevenson \& Ardakani (1972), por meio de vários grupos funcionais, entre eles os grupos carboxílico, fenólico, alcoólico, enólico, amino e imino. Segundo Hodgson (1963), os grupos carboxílicos e fenólicos parecem ser os mais importantes no suprimento de sítios para complexação.

Além de agir diretamente na retenção de metais no solo, a matéria orgânica tem também uma ação indireta ao ligar-se aos argilominerais e óxidos da fração argila. Essas ligações se dão, normalmente, através de pontes de hidrogênio e forças de van der Waals (Van Olphen, 1963), e determinam modificações nas características das superfícies, alterando seu ponto de carga zero (PCZ) e o potencial elétrico superficial. Essas modificações, com certeza, alterarão a capacidade adsortiva das superfícies afetadas.

A importância dos minerais de argila na retenção de zinco tem sido relatada em vários trabalhos (Shuman, 1975, 1976; Korte et al., 1976). Os mecanismos envolvidos nessa interação podem estar relacionados com a adsorção eletrostática ou com a adsorção específica. Entretanto, somente para algumas situações, como a relatada por Wada \& Abd-Elfattah (1978, 1979), a troca iônica tem sido apontada como o principal mecanismo de retenção de zinco pelas argilas. De maneira geral, a adsorção específica é a principal via de retenção de zinco por esses minerais (Hodgson, 1963). 
Os óxidos e hidróxidos metálicos têm sido apontados como os componentes do solo responsáveis pelas reações químicas que o zinco sofre no meio, por diversos autores, a saber: Shuman (1976); Kalbasi \& Racz (1978). O papel dos óxidos no controle da retenção de zinco torna-se especialmente importante, pois o mecanismo de adsorção envolvido não é, em grande parte, de troca iônica (Cavallaro $\&$ McBride, 1984). Bolland et al. (1977) observaram adsorção, mesmo contra repulsão elétrica da superfície, indicando a ocorrência de adsorção específica. Tal fato tem sido observado tanto para os óxidos cristalinos como para os amorfos (Forbes et al., 1976; Shuman, 1977).

As reações de zinco com os óxidos sofrem um efeito marcante do $\mathrm{pH}$, sendo maior a adsorção com a clevação deste (Okasaki et al., 1986). A influência do $\mathrm{pH}$ sobre a retenção de zinco pelos óxidos não se restringe, porém, aos mecanismos de adsorção, tendo sido observado por Cavallaro \& McBride (1984) que o pH influi, também, nos mecanismos relacionados com a fixação do metal.

Kalbasi et al. (1978) observaram uma elevação na razão entre adsorção específica e adsorção eletrostática com o aumento do $\mathrm{pH}$, indicando uma importância maior da primeira, mesmo em valores mais elevados de $\mathrm{pH}$. Os mesmos autores sugeriram dois mecanismos de adsorção de zinco pelos óxidos. No primeiro, envolvendo adsorção eletrostática, ocorria a liberação de um íon $\mathrm{H}^{+}$para cada zinco adsorvido, que, neste caso, aparecia como complexo $\mathrm{ZnCl}^{-}$. Esse mecanismo, dependendo do $\mathrm{pH}$, era responsável por entre 8 e $44 \%$ da adsorção de zinco pelos óxidos de ferro. No segundo mecanismo, era observada a liberação de dois $\mathrm{H}^{+}$para cada $\mathrm{Zn}^{2+}$ adsorvido, com a adsorção passando de 56 para $92 \%$ nos óxidos de ferro. Neste último mecanismo, o zinco era adsorvido mesmo abaixo do ponto isoelétrico dos óxidos, sugerindo ligação química. A liberação de $\mathrm{H}^{+}$revela, segundo Kalbasi \& Racz (1978), o envolvimento dos grupos $\mathrm{OH}$ e $\mathrm{OH}_{2}$ da superfície dos óxidos. Forbes et al. (1976) também verificaram a liberação de dois moles de $\mathrm{H}^{+}$para um mol de zinco adsorvido. Segundo esses autores, os hidrogênios liberados podcriam, entretanto, ter-se originado da superfície dos óxidos ou da hidratação dos íons metálicos.
Kalbasi \& Racz (1978) observaram que os teores de zinco no solo, extraídos através de digestão nitroperclórica, estavam significativamente correlacionados com os teores de ferro e, em menor nível de significância, com os de alumínio, ambos extraídos com oxalato. Outros estudos confirmam a maior influência dos óxidos, amorfos, tendo sido observados maiores valores para zinco adsorvido nesses óxidos em relação àqueles com maior grau de cristalização (Cavallaro \& McBride, 1984; Okasaki et al., 1986).

Shuman (1977) estimou, com base na equação de Langmuir, a mesma capacidade adsortiva para goetita e gibsita. Entretanto, os óxidos de ferro e alumínio amorfos apresentavam uma capacidade de adsorção para zinco muito maior que os cristalinos. Essa maior capacidade adsortiva dos amorfos estava altamente correlacionada com a CTC e com a superfície específica, muito maior nesses óxidos.

Segundo Bolland et al. (1977), outros fatores podem influir na adsorção de zinco pelos óxidos, entre eles a natureza dos ânions presentes na solução do solo; observaram eles ligeira elevação na adsorção de zinco na presença de fosfato, possivelmente pelo fato de este ânion elevar o potencial de adsorção específica dos óxidos.

O objetivo do presente estudo foi verificar quais os atributos do solo que mais influenciam a retenção do zinco em diversos solos paulistas.

\section{MATERIAL E MÉTODOS}

Solos - Foram utilizadas amostras dos horizontes A e B de sete solos do Estado de São Paulo, classificados por Oliveira et al. (1979). As unidades utilizadas foram: Latossolo Roxo eutrófico, unidade Ribeirão Preto - LRe, Typic Eutrorthox; Latossolo Vermelho-Escuro, álico, textura argilosa, unidade Limeira - LE-1, Typic Haplorthox; Latossolo Vermelho-A marelo, álico, textura média, unidade Laranja Azeda - LV-3, Typic Haplorthox; Latossolo Vermelho-Escuro, álico, textura média, unidade Hortolândia - LE-4, Typic Haplorthox; Podzólico Vermelho-Amarelo, abrupto, textura arenosa/média, unidade Alva - PV-1, Arenic Abruptic Paleudult; Podzólico Vermelho-Amarelo, textura 
argilosa, unidade Valinhos - PV-6, Typic Paleudult; Terra Roxa Estruturada eutrófica, unidade Babilônia - TE, Rhodic Paleudalf.

Após a coleta, os solos foram secos ao ar e peneirados com peneira de plástico com abertura de malha de $2 \mathrm{~mm}$.

Caracterização física e química dos solos Utilizando os métodos apresentados por Camargo et al. (1986), as amostras foram analisadas para as seguintes características físicas e químicas: argila, $\mathrm{pH}$ em $\mathrm{H}_{2} \mathrm{O}, \mathrm{pH}$ em $\mathrm{KCl} 1 \mathrm{~N}$, carbono orgânico total, capacidade de troca catiônica (CTC) ao $\mathrm{pH}$ 7,0 com acetato de amônio, ferro, alumínio e manganês extraíveis em ditionito-citrato-bicarbonato, oxalato de amônio e ataque sulfúrico.

Adsorção de zinco nos solos - Em tubos de centrífuga de $50 \mathrm{ml}$, amostras de $2,00 \mathrm{~g}$ dos solos, tomadas em duplicata, foram suspensas em $200 \mathrm{ml}$ de uma solução $0,002 \mathrm{M}$ de $\mathrm{CaCl}_{2}$ na concentração de $2 \mathrm{~mol} / \mathrm{m}^{3}$ contendo zinco como $\mathrm{ZnCl}_{2}$, nas concentrações de $0 ; 0,3 ; 0,6 ; 0,9 ; 1,5 ; 3,0 ; 6,0 ; 9,0$; 12,0 e $24,0 \mathrm{mg} / \mathrm{dm}^{3}$. O período de agitação das suspensões foi estabelecido com basc em ensaios preliminares, tendo sido atingido o equilíbrio do zinco com as amostras após 15 horas de agitação.

Ao final desse período, as suspensões foram centrifugadas a $10.000 \mathrm{rpm}$ por vinte minutos, filtrando-se, em seguida, o sobrenadante em membrana de $0,45 \mu \mathrm{m}$ para remoção das partículas em suspensão.

Após a filtragem, determinaram-se no filtrado o pH da solução e a concentração de zinco, esta por espectrofotometria de absorção atômica; a quantidade adsorvida pelo solo foi calculada pela diferença entre as concentrações iniciais e finais de zinco na solução de equilíbrio.

Isotermas de adsorção - A partir dos dados obtidos experimentalmente, construíram-se isotermas de adsorção, relacionando-se a quantidade de zinco adsorvido com a concentração na solução de equilíbrio. Com base em análise de regressão não linear, foram obtidos os coeficientes das equações de Freundlich e Langmuir, cujos modelos utilizados foram os seguintes:

$$
\text { Freundlich: } \mathrm{X}=\mathrm{K}_{\mathrm{F}} \mathrm{C}^{\mathrm{b}}
$$

onde:

$\mathrm{X}$ : quantidade de zinco adsorvido (mg/kg); C: concentração de zinco na solução de cquilíbrio $\left(\mathrm{mg} / \mathrm{dm}^{3}\right)$ e $\mathrm{K}_{\mathrm{F}}$ e $\mathrm{b}$ : constantes.

$$
\text { Langmuir: } \mathrm{X}=\mathrm{K}_{\mathrm{L}} \mathrm{MC} /\left(1+\mathrm{K}_{\mathrm{L}} \mathrm{C}\right)
$$

onde:

$\mathrm{X}$ : quantidade de zinco adsorvido $(\mathrm{mg} / \mathrm{kg}) ; \mathrm{C}$ : concentração de zinco na solução de equilíbrio $\left(\mathrm{mg} / \mathrm{dm}^{3}\right) ; \mathrm{M}$ : adsorção máxima $(\mathrm{mg} / \mathrm{kg})$ e $\mathrm{K}_{\mathrm{L}}$ : coeficiente relativo à energia de ligação $\left(\mathrm{dm}^{3} / \mathrm{mg}\right)$.

\section{RESULTADOS E DISCUSSÃO}

Com o objetivo de identificar os principais atributos dos solos envolvidos na adsorção de zinco, procedeu-se às análises de regressão linear simples e múltipla entre os valores desses atributos e os parâmetros das equações de Freundlich e Langmuir. Os atributos selecionados foram os seguintes: $\mathrm{pH}$, CTC, teores de argila e matéria orgânica, óxidos de ferro, alumínio e manganês extraíveis com citrato-ditionito-bicarbonato, oxalato de amônio e ácido sulfúrico. Os resultados encontram-se no quadro 1 .

Análise de regressão simples - As equações obtidas, bem como os coeficientes de correlação resultantes da análise de regressão simples para os parâmetros das equações de Freundlich e Langmuir e os atributos dos solos, encontram-se no quadro 2.

Com esse procedimento, foi possível identificar o óxido de ferro em sua forma menos cristalizada (extraível em oxalato) como sendo o constituinte mais relacionado com a energia de ligação do zinco às partículas do solo, seguido de perto pelos óxidos de ferro extraíveis com ácido sulfúrico e ditionito.

Obtiveram-se também altos coeficientes de correlação para o teor de argila, pH e óxidos de alumínio extraíveis com oxalato e ácido sulfúrico, ao contrário da CTC e da matéria orgânica, cujos coeficientes foram baixos. 


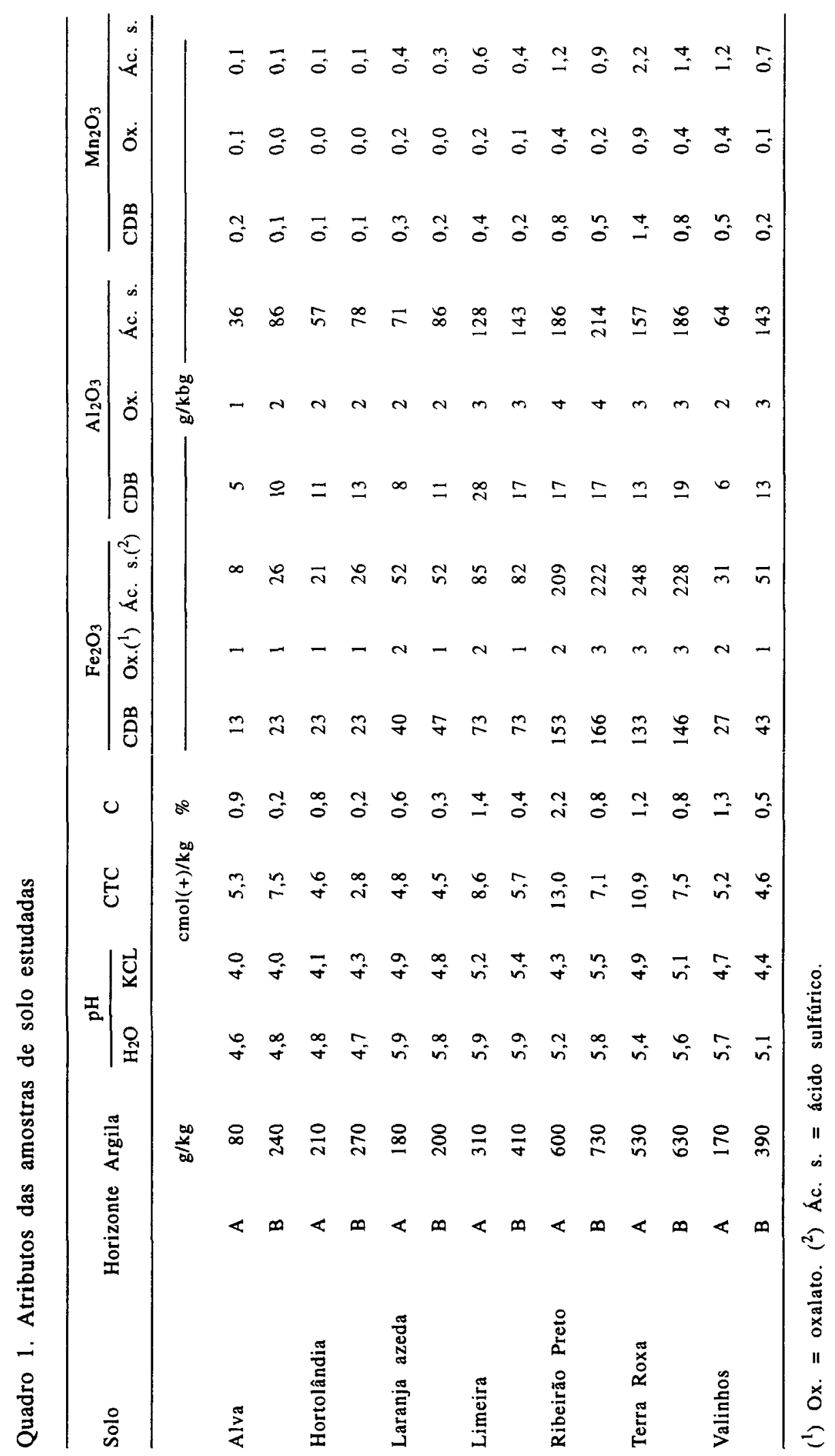




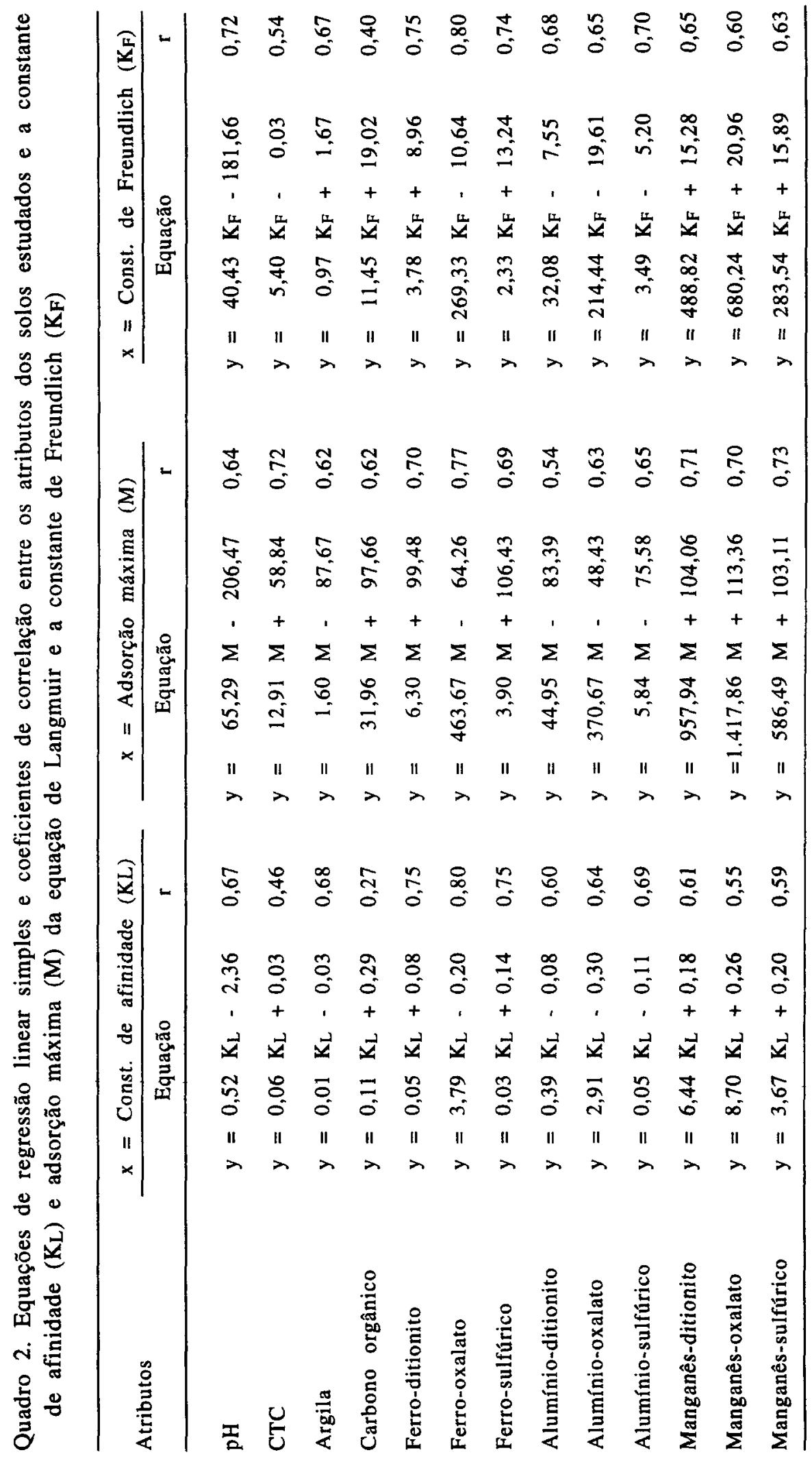


A constatação de que o óxido de ferro em sua forma menos cristalizada é importante na adsorção de zinco encontra apoio na observação de Okasaki et al. (1986), ao verificar adsorção decrescente desse elemento, do cobre e do magnésio com o aumento do grau de cristalização dos óxidos e hidróxidos de ferro. Abd-Elfattah \& Wada (1981) também identificaram os óxidos de ferro como componentes mais seletivos para a adsorção de chumbo, cobre, zinco, cobalto e cádmio do que caulinita, alofana, húmus e montmorilonita. Essa maior seletividade, segundo esses autores, pode estar associada à maior estabilidade dos complexos de coordenação dos metais pesados envolvendo grupos $\mathrm{OH}$ ou $\mathrm{COOH}$ desprotonados como ligantes.

Shuman (1977), estudando a adsorção de zinco em óxidos, observou igualmente uma influência maior das formas menos cristalizadas de óxidos hidratados de ferro e alumínio sobre a adsorção de zinco, e valores mais elevados do coeficiente $\mathrm{K}$ da equação de Langmuir para tais formas de óxidos. Concluiu, entretanto, que as formas menos cristalizadas obtidas em laboratório podem proporcionar resultados errôneos, se comparados às características de adsorção dos óxidos de ferro e alumínio encontrados nos solos.

A maior correlação observada entre o coeficiente $\mathrm{K}$ da equação de Langmuir e os óxidos pode ser explicada tendo em vista o fato de o maior percentual da adsorção no solo ser de natureza química, como também observaram Roesch (1979) e Kiekens (1975), envolvendo, portanto, uma energia de ligação maior.

Para o coeficiente $M$ da equação de Langmuir, as propriedades dos solos que apresentaram coeficientes de correlação mais elevados foram os óxidos de ferro e manganês e a CTC, embora as demais propriedades também apresentassem coeficientes de correlação relativamente elevados.

De maneira geral, a adsorção química tem sido relatada como o principal mecanismo de retenção de zinco em solos. Roesch (1979), por meio de dados obtidos a partir de curvas que relacionam zinco em solução e pH, em dois sistemas - um contendo cloreto de cálcio $0,005 \mathrm{M}$ e outro, cloreto de potássio $1 \mathrm{M}$ - concluiu que acima de $\mathrm{pH}$ 5,3 a adsorção química era superior à eletrostática, para todos os solos utilizados no experimento. Da mesma forma, Kiekens (1975) encontrou maiores valores para zinco adsorvido quimicamente do que eletrostaticamente para os três solos utilizados em seu estudo, sendo maior o percentual de zinco adsorvido por esse mecanismo, principalmente para os solos argilosos.

A identificação da adsorção química como o principal mecanismo de retenção de zinco em solos contribui para explicar a alta correlação obtida para adsorção máxima e teores de óxidos (Quadro 3).

Shuman (1977) constatou maiores valores de adsorção máxima, estimada pelo coeficiente $M$ da equação de Langmuir, para os óxidos de ferro e alumínio amorfos, do que para os cristalinos. Essa conclusão, entretanto, não coincide com os dados do quadro 2. Verifica-se que para os solos estudados não houve diferença significativa entre as formas cristalinas e amorfas dos óxidos, extraídos com CDB ou oxalato de amônio. Pode-se observar, da mesma forma, uma correlação maior entre $\mathbf{M}$ e os óxidos de ferro e manganês em relação aos de alumínio. Também a CTC apresentou boa correlação com a adsorção máxima, confirmando as observações de Shuman (1975) para solos e para fração argila dos solos, assim como as de Elsakkary (1979), que observou alta correlação entre M e CTC, teor de argila e $\mathrm{Fe}_{2} \mathrm{O}_{3}$ livres.

O coeficiente $\mathrm{K}$ da equação de Freundlich apresentou resultados diferentes dos observados para o coeficiente $\mathbf{M}$ de Langmuir. As propriedades dos solos que se mostraram significativamente correlacionadas com esse parâmetro foram óxidos de ferro, seguidos do $\mathrm{pH}$ e óxidos de alumínio extraídos com ácido sulfúrico.

Em que pese a alta correlação existente entre os coeficientes $\mathrm{K}$ de Freundlich e $\mathrm{M}$ de Langmuir $(r=0,87)$, fica difícil sugerir uma associação definitiva entre ambos, tendo em vista a natureza empírica da equação de Freundlich. 


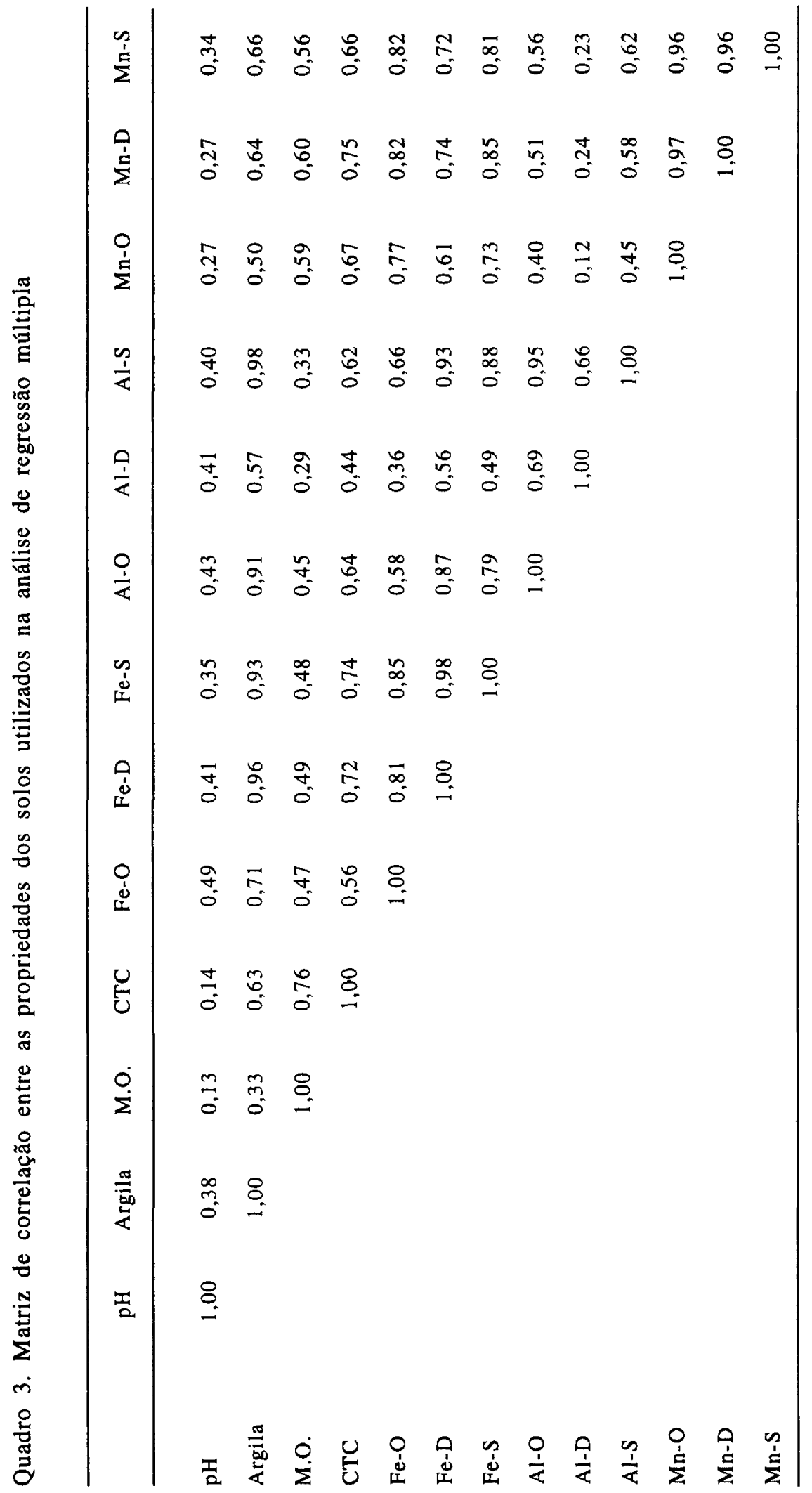


Análise de regressão múltipla - Considerando-se a natureza heterogênea dos solos e a possibilidade de várias de suas propriedades estarem associadas com os mecanismos de adsorção de zinco, decidiu-se pela realização de uma análise de regressão e correlação múltiplas.

Os modelos assim obtidos foram ajustados e, suas significâncias, testadas para os coeficientes $\mathrm{M}$ e $\mathrm{K}$ de Langmuir e $\mathrm{K}$ de Freundlich. Os níveis descritivos associados à estatística F-Fisher possibilitam atestar a adequabilidade dos modelos que identificam as variáveis relativas aos coeficientes das equações de adsorção.

Com o auxílio da análise de regressão múltipla, é possível verificar o efeito conjunto das propriedades dos solos sobre a energia de ligação do zinco; assim, verificou-se que a influência das propriedades do solo decresceu na seguinte ordem: $\mathrm{pH}$, Fe-oxalato e Al-ditionito. As demais propriedades não apresentaram influência significativa sobre esse parâmetro.

Esses resultados confirmam a maior influência dos óxidos sobre o parâmetro $\mathrm{K}$, como observado na análise de regressão simples (Quadro 2), e confirmam também a influência do pH. Entretanto, a exclusão dos óxidos de ferro extraíveis com ditionito e ácido sulfúrico, dos óxidos de alumínio extraídos com ácido sulfúrico e oxalato e do teor de argila, ao lado da inversão na posição da influência relativa dos constituintes, pode parecer conflitante com a utilização dos dois procedimentos.

Entretanto, pelo quadro 3, onde são apresentadas as correlações entre as propriedades dos solos utilizadas nas análises de regressão múltipla, observa-se que grande parte dessas propriedades se apresentam altamente correlacionadas. Isso pode explicar as distorções observadas entre os dois procedimentos de análise de correlação. Desse modo, a eliminação das formas de óxido de ferro extraíveis com ditionito e ácido sulfúrico do modelo de ajuste entre o coeficiente $K$ da equação de Langmuir e as propriedades dos solos, dá-se pelo fato de estas diferentes formas de ferro estarem altamente correlacionadas, resultando na eliminação daquelas menos significativas no modelo final. O mesmo pode ter ocorrido com as formas de óxido de manganês, altamente correlacionadas com as de ferro extraíveis com oxalato.

A análise de regressão múltipla apresenta-se, portanto, como um procedimento mais adequado, por possibilitar a avaliação da influência concomitante dos diversos constituintes dos solos sobre o parâmetro em questão.

Para a adsorção máxima, estimada pelo coeficiente $\mathbf{M}$ da equação de Langmuir, o modelo obtido pela análise de regressão múltipla é o seguinte:

$$
\mathrm{M}=-275,0039+64,0129 \mathrm{pH}+14,4811 \mathrm{CTC} .
$$

Nesse modelo, as propriedades mais significativamente correlacionadas com $\mathrm{M}$ foram CTC e $\mathrm{pH}$. De acordo com ele, $42 \%$ da adsorção máxima estimada pela equação de Langmuir é explicada pela CTC e $41 \%$ pelo $\mathrm{pH}$.

Mais uma vez a utilização da análise de regressão múltipla proporcionou diferenças significativas em relação à análise de regressão simples. Esta última apresentou coeficientes de correlação praticamente iguais para todas as propriedades. Entretanto, desconsiderando-se o efeito cumulativo dessas propriedades, para o qual pode-se ter uma idéia a partir da matriz de correlação entre as propriedades (Quadro 3), o que se observa é grande redução no número de propriedades significativamente correlacionadas com o coeficiente testado.

Essas propriedades não consideradas no modelo obtido pela análise de regressão múltipla poderiam ser nele incluídas, em substituição a outras com as quais se encontram correlacionadas. Entretanto, tal artifício traria como conseqüência uma redução do valor do coeficiente de determinação do modelo, obtido com auxílio da análise da variância. Para o modelo obtido, foi observado alto coeficiente de determinação $(0,84)$, atestando a sua adequação.

Singh \& Sekhon (1977), estudando o efeito das propriedades de sete solos alcalinos sobre a adsorção de zinco, observaram que para uma análise de regressão linear simples entre o coeficiente relativo à adsorção máxima, M, e propriedades dos solos, os teores de argila, matéria orgânica e CTC foram correlacionados, ao contrário do $\mathrm{pH}$, que apresentou 
baixo coeficiente de correlação. Entretanto, analisando as propriedades em conjunto, observaram que os coeficientes de correlação parciais obtidos para argila e matéria orgânica eram dependentes da CTC.

Essa dependência da matéria orgânica pela CTC também foi observada, tendo-se em conta a alta correlação entre essas propriedades, como se pode verificar no quadro 3 , a partir do coeficiente de determinação obtido $(0,76)$.

A análise de regressão múltipla entre as propriedades dos solos e o coeficiente $K$, da equação de Freundlich, evidenciou a correlação entre o coeficiente e algumas propriedades já identificadas como significativas na análise de regressão simples. Entre elas, mostraram-se correlacionados com K os óxidos de alumínio extraídos com $\mathrm{CDB}$ e os óxidos de ferro extraídos com oxalato. O modelo obtido apresentou um elevado coeficiente de determinação $(0,85)$. Através desse modelo, $51 \%$ do parâmetro $\mathrm{K}$ é explicado pelo $\mathrm{pH}, 26 \%$ pelo óxido de ferro extraído com oxalato e $11 \%$ pelo óxido de alumínio extraído com CDB.

\section{REFERÊNCIAS BIBLIOGRÁFICAS}

ABD-ELFATTAH, A. \& WADA. K. Adsorption of lead, cooper, zinc, cobalt and cadmium by soils that differ in cation exchange materials. The Journal of Soil Science, London, 32(2):271-183, 1981.

BOLLAND, M.D.A.; POSNER, A.M. \& QUIRK, J.P. Zinc adsorption by goethite in the absense and presence of phosphate. Australian Journal of Soil Research, Melbourne, 15(3):279-286, 1977.

CAMARGO, O.A.; MONIZ, A.C.; JORGE. J.A. \& VALADARES, J.M.A.S. Métodos de análise química, mineralógica e física de solos do Instituto Agronômico. Campinas, Instituto Agronômico, 1986. 94p. (Boletim técnico, 106)

CAVALLARO, N. \& McBRIDE,M.B. Zinc and cooper adsorption and fixation by an acid soil clay: effect of selective dissolutions. Soil Science Society of America Proceedings, Madison, 48(5):1050-1054, 1984.
ELSAKKARY, I.H. The chemical fractionation of soil zinc and its specific and total adsorption by Egyptian alluvial soils. Plant and Soil, Wageningen, 53:117$129,1979$.

FORBES, E.A.; POSNER, A.M. \& QUIRK, J.P. The specific adsorption of divalent $\mathrm{Cd}, \mathrm{Co}, \mathrm{Cu}, \mathrm{Pb}$, and $\mathrm{Zn}$ on goethite. Journal of Soil Science, London, 27:154-166, 1976.

HODGSON, J.F. Chemistry of the micronutrient elements in soils. Advances in Agronomy, New York, 15:119-159, 1963.

HODGSON, J.F.; LINDSAY, W.L. \& TRIERWEILER, J.F. Micronutrient cation complexing in soils solution: II. Complexing of zinc and copper in displaced solution from calcareous soils. Soil Science Society of America Proceedings, Madison, 30:723-726, 1966.

KALBASI, M. \& RACZ, G.J. Association of zinc with oxides of iron and aluminum in some Manitoba soils. Canadian Journal of Soil Science, Manitoba, 58:6168, 1978.

KALBASI, M.; RACZ, G.J. \& LEWEN-RUDGERS, L.A. Reaction products and solubility of applied zinc compounds in some Manitoba soils. Soil Science, Baltimore, 125:55-64, 1978.

KIEKENS, L. Studies on the adsorption and desorption of zinc by soils. Mededelingen van de Faculteit Landbouwwetenschappen Rijksuniversiteit Gent., Ghent 40: 1481-1492, 1975.

KORTE, N.E.; SKOPP, J.; FULLER, W.L.; NIEBLA, E.E. \& ALESII, B.A. Trace element movement in soils: influence of soil physical and chemical properties. Soil Science, Baltimore, 122:330-359, 1976.

LINDSAY, W.L. Chemical equilibria in soils. New York, John Wiley \& Sons, 1979. 449p.

OKASAKI, M.; TAK AMIDOH, KK. \& YAMANE, I. Adsorption of heavy metal cations on hydrated oxides and oxides of iron and aluminum with different crystallinities. Soil Science and Plant Nutrition, Tokio, 32:523-533, 1986.

OLIVEIRA, J.B.; MENK, J.R. \& ROTTA, C.L. Levantamento pedológico semidetalhado dos solos do Estado de São Paulo. Rio de Janeiro, IBGE, 1979. 169p. (Série Recursos Naturais e Meio Ambiente, 5)

ROESCH, V. Fatores que afetam a adsorçāo de zinco em solos. Porto Alegre, 1979. 91p. Dissertação (Mestrado) - Faculdade de Agronomia - Universidade Federal do Rio Grande do Sul, 1979. 
SHUMAN, L.M. The effect of soil properties on zinc adsorption by soils. Soil Science Society of America Proceedings, Madison, 39:454-458, 1975.

SHUMAN, L.M. Zinc adsorption isotherms for soil clays with and without iron oxides removed. Soil Science Society of America Proceedings, Madison, 40:349$352,1976$.

SHUMAN, L.M. Adsorption of $\mathrm{Zn}$ by $\mathrm{Fe}$ and $\mathrm{Al}$ hydrous oxides as influenced by aging and $\mathrm{pH}$. Soil Science Society of America Proceedings, Madison, 41:703$706,1977$.

SHUMAN, L.M. Effect of ionic strength and anions on zinc adsorption by two soils. Soil Science Society of America Proceedings, Madison, 50:1438-1442, 1986.

SINGH, B. \& SEKHON, G.S. The effect of soil properties on adsorption and desorption of zinc by alkaline soils. Soil Science, Baltimore, 124:366-369, 1977.
SPOSITO, G. On the use of the Langmuir equation in the interpretation of "adsorption" phenomena: II. The "two-surface" Langmuir equation. Soil Science Society of America Proceedings, Madison, 46:1147$1152,1982$.

STEVENSON, F.J. \& ARDAKANI, M.S. Organic matter reactions involving micronutrients in soils. In: MORTVEDT, J.J.; GIORDANO, P.M. \& LINDSAY, W.L., eds. Micronutrients in Agriculture. Madison, Soil Science Society of America, 1972. cap.5, p.79-114.

VAN OLPHEN, H. An introductick to clay colloid chemistry. New York, Interscience, 1963. $301 \mathrm{p}$.

WADA, K. \& ABD-ELFATTAH, A. Characterization of zinc adsorption sites in two mineral soils. Soil Science and Plant Nutrition, Tokyo, 24(3):417-426, 1978.

WADA, K. \& ABD-ELFATTAH. A. Effects of cation exchange material on zinc adsorption by soils. Journal of Soil Science, London, 30:281-290, 1979. 